\title{
Pedagogia de Humberto Mauro: a natureza em Azulão e O João de Barro
}

Eduardo Gruzman

Biólogo, mestre em Tecnologia Educacional nas Ciências da Saúde - Universidade Federal do Rio de Janeiro - Núcleo de Tecnologia Educacional para a Saúde (NUTES).

E-mail: egruzman@ig.com.br

Anita Leandro

Professora adjunta de Cinema e Vídeo da Universidade Federal do Rio de Janeiro Núcleo de Tecnologia Educacional para a Saúde (NUTES), pesquisadora Faperj.

E-mail: anitadebengy@bol.com.br

Observamos atualmente uma crescente utilização da tecnologia do vídeo para a produção de materiais educativos, porém sem a contrapartida de uma necessária reflexão sobre a linguagem cinematográfica e sobre a própria educação. Preocupada apenas em transmitir determinados conteúdos, a escola, muitas vezes, utiliza o audiovisual como simples recurso técnico capaz de levar conceitos aos alunos. "Prevalece ainda hoje aquela pedagogia do transporte, da mensagem a ser transmitida ${ }^{1}$." A imagem, por servir apenas como ilustração de um discurso precedente, "acaba tendo uma participação secundária na maioria dos processos educativos que a utilizam".

Assim, como a educação não problematiza suficientemente a linguagem audiovisual do ponto de vista formal, interessada sobretudo no conteúdo a ser passado, os vídeos educativos, por sua vez, acabam reproduzindo, de modo geral, a estética dominante da televisão e do cinema comercial que, com sua submissão à continuidade narrativa, seus planos de curta duração e sua voz em off condicionando as imagens ao que está sendo dito, impede muitas vezes que o espectador tenha uma relação mais direta com o objeto filmado. Essa estética não estimula o estabelecimento de um diálogo entre espectador e imagens, impedindo assim que ele possa realmente aprender com aquilo que observa.

Antes de avançarmos nessa discussão, o que será feito ao longo da análise dos filmes de Humberto Mauro, procuraremos entender melhor o contexto histórico no qual se insere a produção educativa do cineasta, bem como os fatores que concorreram para a criação do Instituto Nacional de Cinema Educativo (INCE).

1. LEANDRO, A. Da imagem pedagógica à pedagogia da imagem. Comunicação \& Educação, São Paulo: CCA/ECA/USP/ Moderna, n. 21, p. 29-36, maio/ago. 2001.

2. Ibid. 
3. SOUZA, C. R. Catálogo de filmes produzidos pelo INCE. Rio de Janeiro: Fundação do Cinema Brasileiro, 1990. Mimeografado.

4. VIDAL, D. G. A imagem na reforma educacional carioca da década de 20: fotografia, cinema e arquitetura. In: Seminário Pedagogia da imagem, imagem da pedagogia. Anais. Niterói: Universidade $\mathrm{Fe}$ deral Fluminense, 1995. p. 175.

5. MORETTIN, E. V. Cinema, história e educação: uma análise do filme "Os Bandeirantes", de Humberto Mauro. In: Seminário Pedagogia da imagem, imagem da pedagogia. Anais. Niterói: Universidade Federal Fluminense, 1995. p. 181.

6. PINTO, R., apud CÉSAR, A. C. Literatura não é documento. Rio de Janeiro: Funarte, 1980. p. 18.

\section{INCE}

Inspirado no projeto mussoliniano de cinema educativo ${ }^{3}$, o INCE foi fundado em 1937 pelo governo Getúlio Vargas, através do então Ministro da Educação e Saúde, Gustavo Capanema. No mesmo ano da fundação do Instituto, Humberto Mauro foi nomeado seu diretor-técnico. Até 1967, ano de sua aposentadoria e da extinção do INCE, o cineasta dirigiu cerca de 357 filmes pelo instituto, entre curtas, longas e médias-metragens; uma filmografia vasta e de grande importância na história do cinema brasileiro.

A criação do INCE foi resultante de uma prolongada campanha realizada por alguns educadores e intelectuais da época que, liderados pelo antropólogo Edgard Roquette Pinto, defendiam a criação de uma instituição estatal destinada à produção e exibição de filmes educativos no Brasil. Eles se baseavam em três argumentos principais. Um primeiro argumento dos educadores era a necessidade de se introduzir os princípios da Escola Nova nos currículos brasileiros. Valorizando uma educação fundada na experiência e com ênfase na associação entre prática e teoria, a Escola Nova propunha um método ativo e pragmático de educação, privilegiando "a experimentação como meio de aquisição de conhecimentos escolarizados, viabilizada por atividades de observação e participação dos alunos em classe, laboratórios e excursões" ${ }^{4}$. Nesse contexto, onde o ver passa a ser essencial nos processos educativos, começava-se a acreditar nas potencialidades do cinema aplicado à educação.

Um segundo argumento, condizente com o sentimento desenvolvimentista do Estado Novo, era relativo à intenção de promover a escolarização das massas. A criação de um órgão de produção de filmes educativos no Brasil assentava-se sobre a crença de que o cinema seria um instrumento valioso para promover a educação, principalmente num país de analfabetos como o Brasil.

Um terceiro argumento para justificar a produção de filmes educativos por uma instituição estatal era quanto à preocupação com a qualidade dos filmes exibidos para o público, sobretudo crianças, e a necessidade de produzir obras sadias, segundo os educadores. A identificação de uma possível ameaça representada pelo cinema fez com que os educadores orientassem suas ações no sentido de solicitar a intervenção do Estado no controle e na produção de filmes educativos ${ }^{5}$.

Assim, preocupado com o controle das mensagens cinematográficas e com a transmissão de idéias necessárias a um desenvolvimento intelectual e sadio do povo, o Governo cria o INCE. Este órgão produziria os filmes educativos e seria responsável pela distribuição deles em todo o país. Roquette Pinto, um dos principais articuladores do projeto e nomeado diretor-presidente do órgão, procurou desde o início traçar características e padrões desejados para um filme educativo: "nítido, minucioso, detalhado, claro, sem dubiedades para a interpretação dos alunos; lógico no encadeamento de suas seqüências; movimentado, porque no dinamismo existe a primeira justificativa do cinema; interessante no seu conjunto estético e nas suas minúcias de execução, para atrair, em vez de aborrecer"6. 
No interior dessas diretrizes formuladas por Roquette Pinto, percebemos uma concepção de educação que acredita na transmissão do conhecimento. Filmes que sejam nítidos, claros, detalhados e sem dubiedades para a interpretação dos alunos, revelam uma visão de educação sustentada por certa pedagogia diretiva, em que o aluno apenas recebe passivamente informações previamente elaboradas, sem ter possibilidade para a interpretação e construção de seus próprios conceitos.

Atualmente, observamos na pedagogia uma mudança de paradigma. Se antes os modelos pedagógicos eram baseados na transmissão de conhecimentos, hoje eles se baseiam no modelo construtivista, que tem como pressuposto básico a idéia de que o indivíduo é o agente ativo na construção do seu próprio conhecimento. A partir de sua interação com a realidade física e social, o indivíduo constrói seu conhecimento baseado em experiências e noções anteriores.

Se estamos interessados na produção de filmes e vídeos educativos coerentes com os pressupostos construtivistas de aprendizagem, que sejam capazes de oferecer elementos para o trabalho intelectual do espectador, oferecendo-lhe espaço para construir seu próprio conhecimento, por que então escolhemos analisar os filmes de Humberto Mauro, cineasta subordinado às diretrizes do INCE? É porque aí, onde havia uma expectativa oficial em relação à linguagem dos filmes educativos, Humberto Mauro conseguiu, de certa forma, exercer seu potencial criador. Se por um lado seus filmes atendiam às encomendas do Estado, por outro eram totalmente transgressores, escapando ao rígido didatismo burocrático, utilizando a poesia, a metáfora e a pausa reflexiva, elementos que não eram previstos pelas diretrizes oficiais ${ }^{7}$. É neste ponto que a obra de Humberto Mauro nos interessa: ao burlar a estética estadonovista, criando novas possibilidades de tratamento das imagens e dos sons, seus filmes oferecem lições de pedagogia que nos ajudam a pensar a utilização do audiovisual nos contextos educacionais contemporâneos.

\section{O CONSTRUTIVISMO DE HUMBERTO MAURO}

Analisaremos a seguir dois filmes educativos do cineasta mineiro Humberto Mauro, Azulão $(1948)^{8}$ e O João de Barro $(1956)^{9}$, buscando nessas obras contribuições para uma discussão a respeito do filme educativo e da aprendizagem com imagens.

O filme Azulão faz parte da série Brasilianas, produzida pelo INCE entre os anos de 1945 e 1958. Nessa série, Humberto Mauro faz pequenos filmes sobre folclore e canções populares, em que são apresentadas algumas canções conhecidas, com apoio de imagens que, de certa forma, vão ilustrando a letra da música. Os dois planos iniciais de Azulão, já com a presença da música, mostram uma ampla paisagem seguida da imagem de uma casa e seu ambiente de entorno. Posteriormente, após um plano em que o sertanejo tira o azulão da gaiola, segue uma tomada de dentro da casa, mostrando o interior quase totalmente escuro e uma janela que enquadra uma paisagem clara do lado
7. Ibid., p. 20 .

8. BRASILIANAS. Canções Populares - II: interpretação das canções populares Azulão e Pinhal. Direção: Humberto Mauro. Produção: INCE/IBAC/ Funarte/MINC, 1948 (7 $\min .), P \& B$.

9. O JOÃO de barro. Direção: Humberto Mauro. Produção: INCE/IBAC/ Funarte/MINC, 1956 (21 min.), P\&B. 
de fora. O contraste entre claro e escuro é bastante acentuado e a paisagem vista através da janela convida o espectador a uma atitude de contemplação da natureza. O homem solta o pássaro que sai pela janela e voa em direção à paisagem. A liberdade conquistada pelo pássaro expressa tanto na letra da música ("vai azulão, azulão companheiro vai, vai ver minha ingrata...") quanto no conteúdo da cena um sentido metafórico: o pássaro sai da escuridão enclausurada e voa para a luz, sem grades e sem fronteiras. A dimensão poética da canção encontra ressonância na composição pictural do plano.

Nos três planos seguintes, quando ainda ouvimos a canção, aparecem imagens de um sertão vazio, sem casas, nem pessoas, completamente desmatado. O pássaro, por sua vez, não aparece mais. As imagens, portanto, não mais se referem diretamente à letra da música, uma vez que não se mostra o azulão procurando a "ingrata". Ao contrário, a relação entre a letra e as imagens do sertão é subjetiva, poética, exigindo do espectador uma interpretação, uma construção de sentido a partir do caráter abstrato das imagens e de sua independência em relação à banda sonora. O filme, assim, oferece ao espectador uma situação de aprendizagem, a possibilidade de ele próprio construir o significado da obra, contrariando em todos os sentidos as recomendações do INCE de fazer filmes claros, sem dubiedades para a interpretação dos alunos.

Outro aspecto da pedagogia construtivista de Humberto Mauro nesse filme pode ser visto na utilização de planos vazios, desprovidos de ação ou de um conteúdo narrativo movimentado, como nos planos do sertão que sucedem a conquista da liberdade pelo pássaro. Apesar de serem relativamente curtos (10 a 15 segundos), se compararmos, por exemplo, com alguns planos do filme O João de Barro (até 1 minuto), as cenas de paisagem, como já foi dito, se prestam a uma atividade contemplativa. Não há exigência narrativa, isto é, a necessidade de uma imagem que se prolongaria em reação à imagem anterior e que demandaria uma ação para a imagem seguinte. Da mesma forma, não há comentário em off que orientaria uma interpretação unívoca das imagens. Os planos são independentes uns dos outros no seu alcance poético e constituem aquilo que Gilles Deleuze vai chamar de "situações óticas puras"10. Percebe-se aqui, primeiramente, o caráter documentário do filme, na medida em que dá tempo ao espectador para observar o sertão, fazendo com que ele próprio tire suas conclusões com base no que vê. Como diz Deleuze, "um espaço vazio vale antes de mais nada pela ausência de conteúdo possível"11. Numa pedagogia construtivista, cabe ao espectador construir esse conteúdo.

Assim, Humberto Mauro transgride as recomendações de Roquette Pinto tanto ao permitir dubiedades de interpretação quanto ao compor planos fixos de paisagens sem conteúdo narrativo movimentado, contrariando assim a idéia de que no dinamismo existe a primeira justificativa do cinema. Com isso o diretor convida o espectador a pensar e a construir significados, dando tempo para que a aprendizagem aconteça a partir do seu encontro com o filme. A letra

10. DELEUZE, G. A imagem-tempo. São Paulo: Brasiliense, 1990. p. 11

11. Ibid., p. 27. da canção, longe de dominar ou conduzir as imagens, funciona apenas como tema inspirador, mediante o qual Humberto Mauro, com extrema liberdade, cria seu cinema poético. 


\section{RESISTÊNCIA À VOZ AUTORITÁRIA}

O filme O João de Barro procura mostrar os hábitos de vida do pássaro joão-de-barro, com ênfase no processo de construção de seu ninho. Através das imagens e dos comentários, o filme fornece uma série de informações científicas a respeito da ave, como sua distribuição geográfica, os diferentes habitats que ela ocupa, sua coloração, comprimento etc. Apesar de a voz em off ser utilizada para dar algumas informações a respeito do assunto tratado no filme, não serve apenas para ilustrar o conteúdo das imagens. Em alguns momentos, o comentário faz referência a assuntos que não aparecem simultaneamente na tela, como, por exemplo, quando se refere à distribuição da ave no mundo, enquanto vemos na tela o joão-de-barro construindo seu ninho. Assim, embora a voz do locutor seja cultivada e enfática, adotando um tom objetivo e um ritmo contínuo, coerente com as exigências oficiais, percebemos que em alguns momentos ela não é usada da forma convencional. Há, muitas vezes, uma independência entre as imagens e os sons, permitindo ao espectador construir sentidos, uma vez que o comentário não impõe uma leitura única sobre a imagem.

Além dessa relação indireta entre texto e imagens, observada em alguns momentos do filme, podemos notar também que a fala em off não é predominante, sendo as imagens sem narração, por vezes com som ambiente, muito mais constantes. Dos 21 minutos de duração do filme, apenas 6 minutos são destinados à narração, isto é, menos de $30 \%$ do tempo total do filme. Nas produções educativas atuais, verificamos que quase sempre ocorre o oposto: há predomínio total da fala em relação às imagens, a ponto de podermos entender o conteúdo do vídeo sem prestarmos atenção à banda visual, apenas ouvindo a voz do narrador. No filme de Humberto Mauro, ao contrário, a imagem e aquilo que ela nos revela têm papel importante na compreensão do conteúdo. Em $O$ João de Barro, a narração de um acontecimento se dá somente quando já foi visto pelo espectador. Percebemos que o cineasta renuncia, de certa forma, à utilização de uma voz autoritária, onipresente, que faz comentários precisos e inquestionáveis, comumente utilizada em produções educativas. Recusando essa voz dominadora, em que as imagens serviriam somente para ilustrar um saber pronto, Humberto Mauro possibilita ao espectador aprender a partir do que ele vê, e não apenas com o que ouve, já que não há uma voz em off que represente um discurso oficial, um saber já estabelecido a ser transmitido aos espectadores.

\section{O GERAL E O PARTICULAR}

Em O João de Barro, após os créditos iniciais, sucedem alguns planos abertos mostrando um ambiente rural, com suas paisagens, uma casa e uma família passeando. Ao mesmo tempo, o narrador faz comentários gerais a respeito das aves, tais como: "Em todas as regiões do mundo, qualquer que seja o clima, as aves existem e encontram sempre condições de vida". Posteriormente, vemos imagens da família procurando e observando diferentes pássaros. O narrador, 
então, fala: "Cada espécie apresenta particularidades curiosas nos hábitos, nos cantos e na construção dos ninhos, que oferecem as mais variadas formas". Aparecem então ninhos de diferentes espécies, como o sanhaçu, o tico-tico, o joão-teneném e a cambaxirra. É interessante notar que o diretor vai, aos poucos, delimitando o tema, partindo do geral para só depois ir ao particular, possibilitando ao espectador não perder a noção integral do assunto. Primeiro fala das aves de forma genérica. Depois comenta as diferentes particularidades dos seus hábitos, entre eles a construção dos ninhos. Exemplifica primeiro ninhos de diferentes espécies e, só então, entra no assunto central, o ninho do joão-de-barro. Em Azulão, filme anteriormente analisado, Humberto Mauro adota o mesmo método. Começa com planos gerais, mostrando o ambiente em que a casa se insere, para logo em seguida entrar na casa e focalizar a gaiola. O que podemos concluir dessa escolha, uma vez que o diretor poderia ir diretamente ao tema central?

Algumas disciplinas científicas, como a ecologia, por exemplo, nos revelam que todo evento isolado ganha significado apenas quando visto dentro de um sistema mais amplo. É o princípio das propriedades emergentes, segundo o qual a totalidade é maior do que a soma das partes que a constituem. O estudo dos ecossistemas mostra a existência de uma interdependência entre os organismos vivos e o ambiente físico: "Os organismos vivos e o seu ambiente não-vivo estão inseparavelmente inter-relacionados e interagem entre si [...]. Os ecossistemas são ricos em redes de informação, que compreendem fluxos de comunicação físicos e químicos que interligam todas as partes e governam ou regulam o sistema como um todo" 12 . A existência de uma dependência entre os elementos vivos e abióticos, de forma que todos estão inseparavelmente interrelacionados, revela que cada parte é igualmente importante na constituição e, conseqüentemente, na compreensão do todo.

Também no campo da educação, Paulo Freire comenta que é "indispensável ter antes a visão totalizada do contexto para, em seguida, separar ou isolar os elementos ou as parcialidades do contexto, através de cuja cisão se pode voltar com mais claridade à totalidade analisada"13. Percebemos que Humberto Mauro adota em seus filmes educativos um método similar, revelando preocupação inicial com a compreensão da totalidade, partindo em seguida para o estudo do particular. Seus objetos de interesse imediato, como o azulão ou o joão-de-barro, por exemplo, não são apresentados de forma isolada, mas aparecem sempre integrados ao ambiente que ocupam. O diretor, assim, fornece ao espectador primeiro a visão totalizada do contexto, para só depois isolar um elemento individual.

12. ODUM, E. P. Ecologia. Rio de Janeiro: Guanabara, 1988. p. 29.

13. FREIRE, P. Pedagogia do oprimido. Rio de Janeiro: Paz e Terra, 1970 p. 113.

\section{A RELAÇÃO COM O TEMPO}

Após essa delimitação introdutória do espaço, O João de Barro começa a mostrar as etapas de construção do ninho. Ao mesmo tempo em que o narrador vai tecendo alguns pequenos comentários, a câmera mostra longos planos do 
pássaro confeccionando o ninho. A imagem é acompanhada ora por um som ambiente, ora por uma música de fundo. O processo de construção do ninho mostrado nas imagens não é um truque de montagem, mas sim um flagrante, fruto, sem dúvida, de longa espera. Os planos têm todos duração relativamente longa, procurando, sempre que possível, respeitar o tempo real do acontecimento. É evidente que, devido a seu curto tempo de duração, o filme jamais daria conta de mostrar integralmente esse processo. Porém, nos momentos escolhidos pelo diretor para serem filmados, em particular nos planos em que o pássaro constrói seu ninho, ele o faz sem cortes e sem efeitos de montagem. Isto nos remete ao comentário de André Bazin a respeito de uma seqüência de Nanook of the North (Nanook do Norte, de Robert Flaherty, 1928), em que o esquimó Nanook observa pacientemente a foca antes de arpoá-la: "Se a câmera não pode ver tudo, do que ela escolhe para ver, se esforça ao menos para não perder nada" ${ }^{14}$. Para Bazin, o que interessa para o diretor diante de Nanook e o animal é a amplitude real da espera: "Flaherty se limita a nos mostrar a espera, a duração da caça e a própria substância da imagem, seu verdadeiro objeto"15. Em O João de Barro, um plano fixo de um minuto e vários outros planos de 20 a 40 segundos, sem nenhum comentário, revelam apenas o pássaro moldando o ninho ainda em construção. Humberto Mauro, portanto, não está preocupado com o extraordinário, com os momentos cruciais da construção e com o produto final, o ninho, mas, sim, com o registro daquele momento em profundidade, com o acontecimento em sua duração. $\mathrm{O}$ espectador observa como se estivesse presente no momento da filmagem. $\mathrm{O}$ cineasta, poderíamos dizer, coloca o espectador na verdadeira condição de observador, sem impor nenhuma narração constituída a priori.

\section{LEITURA DO MUNDO}

Em seu artigo A evolução da linguagem cinematográfica, André Bazin distingue duas tendências opostas no cinema: existiriam "os diretores que acreditam na

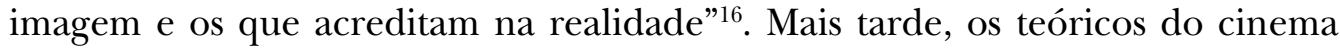
verão nessa dicotomia a distinção entre tradição formal e tradição realista da arte cinematográfica. Na primeira tradição, o cineasta organiza imagens e sons a fim de que sua concepção ou idéia transpareça no filme. O sentido não está presente propriamente nas imagens, mas surge como resultado de relações entre elas, estabelecidas pelo cineasta através do processo de montagem. Já na tradição realista, a imagem, segundo Bazin, vale não pelo que acrescenta à realidade, mas pelo que dela é capaz de revelar. O sentido emana do próprio objeto filmado, e não da montagem ou da intenção do cineasta.

Com base no que acabamos de analisar nos filmes educativos de Humberto Mauro, poderíamos pensar que o cineasta pertence às duas tradições, utilizando ora os métodos da tradição realista, ora os da tradição formal. Quanto à hipótese de que ele acreditaria mais na realidade do que na imagem, temos, sobre isso, uma boa demonstração em um depoimento do próprio cineasta:

14. BAZIN, A. O cinema. São Paulo: Brasiliense, 1991. p. 69

15. Ibid.

16. Ibid., p. 87 
17. Apud FUNARTE. Catálogo da mostra 100 anos de Humberto Mauro. Rio de Janeiro: Ministério da Cultura, 1997. p. 6.

18. FREIRE, P. A importância do ato de ler: em três artigos que se completam. São Paulo: Autores Associados/Cortez, 1989. p. 11.

19. Ibid., p. 13
"Quando vejo uma cachoeira não vou de cara em cima dela, senão ela começa a cair diferente. Me escondo atrás de uma bananeira ou de qualquer outra coisa para poder pegá-la de jeito. Aí ela não sabe que estou filmando. A natureza tem dessas coisas. Natureza a gente não deve filmar quando quer, mas na hora que ela escolhe" ${ }^{17}$.

Percebemos que Humberto Mauro, de certa forma, parecia estar preocupado em descobrir o mundo mediante o cinema, e não em criar uma nova realidade. Captar o verdadeiro sentido de uma cachoeira por meio da câmera só seria possível com muita espera e com muito interesse pela duração real do acontecimento filmado. Seus planos longos, quase sem narração, mostram que ele procurava observar através da câmera, permitindo assim ao espectador observar também.

Eis aí um aspecto importante do método desse cineasta. Como não há discurso pedagógico precedente a ser transmitido, uma vez que ele próprio está envolvido num processo de aprendizagem, de abertura ao novo, o espectador também tem a oportunidade de construir significados a partir da observação, do seu contato prolongado com o mundo filmado, em vez de assimilar um discurso já pronto, um sentido que o narrador ou a montagem viriam atribuir ao mundo real. O educador Paulo Freire, analisando a importância do ato de ler, diz que a leitura do mundo precede sempre a leitura da palavra escrita: "O ato de ler não se esgota na decodificação pura da palavra escrita ou da linguagem escrita, mas se antecipa e se alonga na inteligência do mundo"18. Os textos, as palavras e as letras de suas primeiras leituras se "encarnavam no canto dos pássaros; na dança das copas das árvores sopradas por fortes ventanias que anunciavam tempestades [...]; nas águas da chuva brincando de geografia: inventando lagos, ilhas, rios e riachos [...]"19.

Os filmes educativos de Humberto Mauro, com seus planos relativamente longos (se compararmos com algumas produções educativas atuais) e sem uma narração autoritária, que viria suprimir a força da imagem, nos coloca em situação de descoberta da leitura do mundo. A realidade e toda sua ambigüidade, captada em profundidade, sem cortes e sem uma interpretação prévia, se comunicam mais diretamente com o espectador, exigindo dele a elaboração de uma idéia, de um sentido, de um discurso próprio. Esse cineasta não nos representa a natureza, mas a natureza se apresenta a nós.

Apesar disso, estaríamos cometendo um equívoco se afirmássemos que ele pertence apenas à tradição realista. Como apontamos na análise de seus filmes, muitas vezes trabalha de forma independente a banda sonora e a banda visual, não utilizando, neste caso, o som ambiente como reforço do efeito de realidade. Trabalhando com o texto sonoro e o texto visual de forma separada, exige do espectador a formulação de uma síntese, isto é, uma união de informações visuais e sonoras a fim de construir um sentido.

Assim, seja revelando a natureza na duração dos planos ou acrescentando algo a ela na pista sonora, a questão principal é que, nas suas obras, a dimensão educativa das imagens é alcançada na medida em que o espectador não 
recebe um saber pronto, mas sim um saber a construir. Analisando a maneira como Humberto Mauro trabalha o espaço, isto é, como ele relaciona o geral e o particular, bem como a maneira com que aborda o tempo, encontramos uma grande contribuição para pensarmos a produção contemporânea de vídeos de ensino e educação, em especial na área das ciências biológicas.

Resumo: Observamos atualmente uma crescente utilização do audiovisual na produção de materiais educativos, porém, quase sempre, sem a contrapartida de uma reflexão sobre o alcance pedagógico da imagem em movimento. Interessados sobretudo no conteúdo a ser passado, os vídeos educativos, em geral, acabam reproduzindo a estética da televisão e do cinema industrial, que raramente permite o estabelecimento de uma relação de aprendizagem satisfatória com os filmes. Este artigo analisa dois filmes educativos do cineasta Humberto Mauro: Azulão (1948) e O João de Barro (1956), produzidos pelo Instituto Nacional de Cinema Educativo (INCE). A partir de uma investigação sobre o método do cineasta, tentamos entender como ele representa a natureza em seus filmes. Buscamos com isso contribuições para uma discussão mais aprofundada a respeito da aprendizagem com imagens, avançando algumas sugestões para a produção contemporânea de vídeos educativos.

Palavras-chave: representação da natureza, vídeo educativo, cinema educativo, pedagogia da imagem, Humberto Mauro, INCE.
Abstract: We observed that nowadays there is a growing use of audiovisual in the production of educative materials, although most of these materials don't contain a reflection about the pedagogic scope that images in movement can provide. Interested especially in the contents to be transmitted, most educative videos reproduce the television and industrial cinema esthetic, which rarely allows a satisfactory learning relation with the films. This paper analyzes two educative films of the director Humberto Mauro: Azulão (1948) and $O$ João de Barro (1956), produced by the Instituto Nacional de Cinema Educativo (INCE). Based on an investigation of his method, we tried to understand how he represents nature in these films. We hope to contribute to the discussion about the learning process with images, presenting some suggestions for the production of contemporary educative videos.

Keywords: representation of nature, educative videos, educative cinema, pedagogy of images, Humberto Mauro, INCE. 